\title{
Princípios Teóricos e Práticos do Turismo
}

\author{
Beatriz Helena Gelas Lage*
}

McINTOSH, R.; GUPTA, S. - Turismo - Planeación administración y perspectivas. México, Noriega Editores, 1989, 406 p.

O livro "Turismo - Planeación, Administración y Perspecticas", dos autores Robert McIntosh e Gupta Shashikant, apresenta a versāo espanhola publicada em 1989, pela Noriega Editores, no México, adaptada do original 'Tourism, Principles, Practiques,... Philosophies', editado em 1972 pela Grid, Inc., em Columbus, Ohio.

Nele o turismo é definido como "a ciência, a arte e a atividade de atrair, transportar e alojar viajantes, a fim de satisfazer suas necessidades e seus desejos".

Distribuido em quatro partes, o livro compreende basicamente os aspectos históricos; os princípios da demanda, da oferta e da promoçāo; o planejamento, o desenvolvimento e a economia; e, as práticas e filosofias do Turismo. Tais colocaçōes teóricas e práticas permitem que a obra seja recomendada em cursos universitários de Turismo, além de proporcionar informações e orientaçāo para os mais distintos segmentos do setor, dentre eles: agências de viagens; empresas hoteleiras; companhias transportadoras; e outras entidades, públicas e privadas, interessadas no Turismo como um fator de prosperidade nacional.

A primeira parte - Breve História do Turismo e seus Princípios contém quatro capítulos: Turismo em Perspectiva (1); Turismo Cultural (2); Sociologia do Turismo (3); e, Psicologia e Motivaçāo do Turismo (4).

$\left({ }^{*}\right)$ Livre-Docente pela ECA/USP e Professora Associada do Departamento de Relações Públicas, Propaganda e Turismo da ECA/USP. 
Inicialmente, os autores focalizam o Turismo ao longo do tempo, narrando os deslocamentos dos primeiros viajantes: os fenícios, os po linésios, com destaque para os povos do Mediterrâneo. Neste mesmo capítulo é evidenciada a importância do desenvolvimento dos meios de transporte. Da era antiga ao renascimento; das carroças à evolução aeronáutica; e, de Thomas Cook (1841) a Graf Ferdinand von Zeppelin (1910), grande transformação ocorreu no mundo, com maiores benefícios às viagens, que passaram a ter papel fundamental na sociedade contemporânea.

Em seqüência, os autores mencionam o turismo cultural abordando os principais aspectos das viagens por meio dos quais são conhecidos os costumes e o comportamento dos mais diferentes povos. É o "turismo para ver a vida" que, sem dúvida, propicia um conteúdo educativo para as viagens. Dentre muitos atrativos turísticos fazem referência à arte, música e dança, ao artesanato, à educação, à linguagem e literatura, à ciência, à religião, ao governo, aos alimentos e bebidas e, sem dúvida, à história.

Complementando o assunto, apresentam importantes aspectos sociológicos do Turismo, descrevendo os efeitos que as viagens causam nos indivíduos, nas famílias, nas sociedades e em outros grupos em geral. Propõe uma reflexão das formas institucionalizadas do Turismo Contemporâneo, citando, inclusive, alguns problemas, bem como algumas leituras para discussão e revisão do texto.

As pessoas viajam por várias razões e, portanto, há de se considerar os diferentes aspectos motivacionais e as influências psicológicas de cada indivíduo. Variam segundo o sexo, a idade, a educação, podendo optar por diferentes destinos e por diferentes meios de transporte e alojamento. Neste sentido, cabe lembrar o interessante destaque das principais motivações das viagens por tipos psicográficos, baseada na obra de Stanley C. Plog ("Why Destination Areas Rise and Fall in Popularity"), que descrevem algumas das características psicocêntricas e alocêntricas, extremas e intermediárias.

A segunda parte - Princípios da Demanda, da Oferta e da Promoção do Turismo - contém três capítulos: Demanda Turística (5); Componentes da Oferta do Turismo (6); e, Promoção no Turismo (7).

Como variáveis econômicas responsáveis pelo fluxo turístico, a demanda e a oferta são apresentadas, nesse tópico, por suas respectivas peculiaridades. A curva da demanda, de forma abrangente, é descrita graficamente pela relação entre as quantidades de produtos ou de serviços adquiridos e seus respectivos preços; e, é apresentada como uma função da propensão (predisposição de uma pessoa viajar) e da resistência por viagens (relacionada com o atrativo do destino). A propensão é dependente das características psicográficas e demográficas dos indivíduos; e, a renúncia é dependente da distância econômica da distância cultural, dos custos dos serviços, da qualidade dos serviços e das temporadas.

A oferta turística, por sua vez, é apresentada nesta obra pela classificação geral de seus componentes principais, dentre eles: os recursos naturais (combinação de fatores que podem criar atrativos ambientais para o desenvolvimento turístico); a infra-estrutura (serviços subterrâneos sob a superfície, como, por exemplo, as instalações elétricas, os sistemas de abastecimento de água, os serviços de comunicação etc.); os transportes e seus equipamentos (fatores que propiciam os deslocamentos dos viajantes, desde os serviços de táxi, até as estações ou terminais de partida e de chegada, seja por terra, mar e ar); e, a superestrutura (implicando na construção de hotéis, alojamentos, restaurantes etc.).

Para elevar ao máximo a satisfação dos turistas e para um melhor aproveitamento da força instalada durante o ano, os autores apresentam algumas sugestões no capítulo 7 , que se refere à promoção turística. Recomendam a revisão cuidadosa de algumas perguntas, tais como: Quem são os visitantes atuais e onde vivem? Quais são seus gostos e preferências? Quais são os consumidores potenciais e onde vivem? Qual é a situação de competição do mercado? Que tipo de programa promocional parece ser necessário? Fazem menção, inclusive, sobre as possíveis formas de publicidade, pública e privada, bem como citam um texto sobre a política publicitária no Turismo, de Alan Field, apresentado em Madri no "Tourist Publicity', e publicado pela Organização Mundial de Turismo - OMT, em 1984. Concluem a segunda parte, apresentando uma lista das principais etapas de procedimentos necessários para os planejadores de publicidade do Turismo.

A terceira parte - Planejamento, Desenvolvimento e Economia do Turismo - contém dois capítulos, a saber: Planajamento e Desenvolvimento do Turismo (8); e, Economia do Turismo (9).

Nesta seção, são abordadas as principais metas do desenvolvimento turístico, com destaque para a formulação de planos nacionais, onde a participação do governo tem papel fundamental. É ele quem deve tomar medidas para o fomento turístico, de maneira semelhante aos principais setores produtivos, dentro de uma estrutura de planejamento equilibrado para o desenvolvimento da economia como um todo.

Assim, esse capítulo, evidencia aspectos gerais referentes ao problema econômico - satisfazer as necessidades físicas e psíquicas dos indivíduos (que, geralmente, são ilimitadas) utilizando os diversos recursos à disposição (que, sempre, são limitados). 
Especialmente para o caso do Turismo, há de se reconhecer a importância dos seus principais agentes econômicos envolvidos, ou seja: os turistas, as empresas, o governo e a comunidade anfitriã. Nesse capítulo, os autores abordam os objetivos de cada um desses grupos, além de ilustrarem o texto com explicações gráficas de curvas de indiferença e de restrições orçamentárias, bem como do comportamento dos custos marginais, adotando, como exemplo, o caso específico de uma hipotética empresa hoteleira.

São ainda apresentadas algumas considerações sobre o efeito multiplicador da renda, e de outros macroefeitos gerados pelo Turismo.

Por fim, são feitas algumas colocações econômicas sobre a demanda para o Turismo, dentre elas, comentam algumas de suas principais características, como a elasticidade-preço e a elasticidade-renda.

A quarta e última parte do livro - Práticas e Filosofias do Turismo - contém três capítulos: Como se Organiza o Turismo (10); Investigação em Turismo (11); e, Filosofia para o Futuro do Turismo(12).

Fica bastante claro, com essa abordagem, que a organização do Turismo é muito complexa. O estudo abrange aspectos relacionados à atuação dos principais grupos oficiais de Turismo, em uma análise de suas principais funções, técnicas, e atividades de cooperação mútua. É citado, a título de ilustração, o organograma do órgão público de $\mathrm{Tu}$ rismo canadense, como exemplo de uma organização nacional-mode10.

Também nesta parte é enfatizada a necessidade de investigações e de estudos estatísticos, já que os programas de promoção são patrocinados pelas organizações de Turismo. Essas informações são de extrema importância para uma mais completa e real avaliação do mercado turístico, possibilitando indicações eficientes de melhores oportunidades de promoção pelas organizações, sejam elas privadas, estatais, regionais ou federais.

Concluindo, são escritas algumas das tendências mais significativas que afetam o futuro do turismo, como as tecnológicas, ambientais, e, inclusive, considerações específicas sobre a evolução do tempo livre que, numa civilização industrial moderna, é vital para um maior consumo de produtos turísticos.

Apresenta, ainda, um Glossário de algumas das principais expressões utilizadas pela atividade, como, por exemplo: Agências de Viagem; Destino; Excursionista; Pacotes; Passaportes; Serviços Terrestres; Tarifas; Turismo; Turista; Vôos Charter e outros. Além disso, complementando, estão relacionadas algumas das principais abreviaturas internacionais, tais como: ASTA (Sociedade Americana de Agentes de Viagens); $\mathrm{ABC}$ (Charter reservado com antecipação); DC
(Diner’s Club); FAA (Administração Federal da Aviação); IT (Inclusive Tour); WATA (Associação Mundial de Agentes de Viagens); XO (Ordem de Câmbio); e muitas outras siglas ou termos de uso freqüente na atividade turística.

Finalizando, recomenda-se a leitura atenta dessa obra, de fácil entendimento e evidente aplicação nas mais distintas áreas de conhecimento. Considera-se o livro de McIntosh e de Gupta um valioso instrumento, não só para os estudantes, mas para todos os interessados no campo do Turismo.

\section{“Managing Tourism"}

\section{Doris Van de Meene Ruschmann*}

MEDLIK, S. Managing Tourism. Oxford, Butterworth-Heinemann, 1991, 344 p.

O professor Medlik, organizador desta coletânea de textos, dirigiu durante dez anos o Department of Hotel, Catering and Tourism Management da University of Surrey (Guilford - Inglaterra) e, além de ter mais de uma centena de artigos publicados em revistas técnicas e de "papers" em congressos, escreveu vinte livros sobre Turismo.

Nessa obra, ele reúne as contribuições de trinta especialistas, cujos artigos foram publicados na revista "Tourism Management", durante a década de 1980 e que, devido à importância do seu conteúdo, não perderam a atualidade, servindo de referência para o leitor dos anos 90 , de qualquer parte do mundo.

Os textos selecionados refletem teorias, conceitos e práticas, pois Medlik entende que, no vasto campo do Turismo, a prática sem a fundamentação conceitual é estéril, e a teoria é o resultado de uma seleção de práticas.

Divide a obra em dez partes e cada uma delas apresenta a contribuição de vários autores que abordam diferentes temas de forma abrangente e clara, refletindo a situação da teoria e da prática do Turismo no final da década de 1980, projetando-a para a década de 1990. Os temas abordados são os seguintes: Evolução e Tendências do Turismo Mundial; Planejamento; Gestão e Desenvolvimento de Empresas Turísticas, Políticas Governamentais no Turismo; Con-

(*) Professora Assistente do Departamento de Relaçōes Públicas. Propaganda e Turismo da Escola de Comunicações e Artes da Universidade de Sảo Paulo. 